\title{
La imaginación global y la ética cosmopolita en El asco de Horacio Castellanos Moya
}

Resumen: La crítica ha propuesto que El asco de Horacio Castellanos Moya muestra el desencanto y el cinismo típico de las novelas centroamericanas de "posguerra" que critican el fracaso de los proyectos sociales de carácter utópico. En este trabajo, en cambio, se considera El asco dentro del contexto de un mundo en que el concepto de la nación y específicamente el nacionalismo, en el marco del neoliberalismo, ha entrado en crisis. Arguyo que no hay una estrategia narrativa desencantada que denuncia los errores de la nación, sino una ética que muestra una ruptura con la identidad nacional y el nacionalismo. El tono crítico no debe interpretarse como desencanto dado no hay evidencia de un encanto nacional previo. El monólogo, en cambio, anuncia una renovada ética humanitaria y cosmopolita que ha reemplazado la identificación nacional.

Abstract: Critics have proposed that Horacio Castellanos Moya's El asco is an example of the disillusionment and cynicism typical of Central American "post-war" novels that are characterized by an attitude critical of the failure of utopian social projects. In this article, El asco is considered within the context of a World in which the concept of "nation," more precisely "nationalism," within the framework of neo-liberalism, is in crisis. I argue that El asco's narrative strategy does not reveal cynicism or a condemnation of the errors of the nation, but rather that it demonstrates an ethics that emerges out of a break with national identity and nationalism. I propose that El asco is not an example of disillusionment given that there is no evidence of an earlier fascination with the nation. Instead, El asco's monologue announces that a renewed humanitarian and cosmopolitan ethics has replaced national identity.

Soy ciudadano del mundo.

DIÓGENES EL CÍNICO

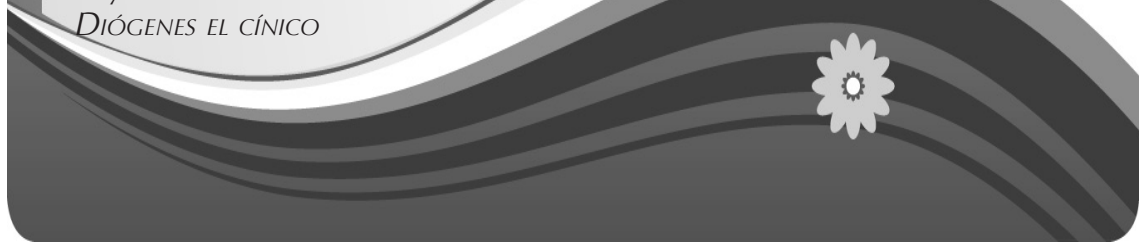


A I preguntarle Natu Poblet a Horacio Castellanos Moya sobre las amenazas de muerte que recibió con la publicación de su novela El asco, el autor le quitó importancia al asunto explicando: "En El Salvador a veces a uno lo amenazan a muerte por marcar el número equivocado." De igual manera, el protagonista de $E I$ asco se enfrenta a lo difícil con un tono impúdico y una perspectiva que posiciona la cultura salvadoreña dentro de un contexto global. Edgardo Vega es un salvadoreño neurótico que vive hace diecinueve años en Canadá y se ve obligado a volver a El Salvador porque muere su madre. Se encuentra con el escritor Moya que ha sido su compañero de colegio. El asco es el largo monólogo de Edgardo Vega acerca del asco y la repulsión que le inspira todo lo que experimenta y ve en El Salvador como la ciudad, la comida, y el aeropuerto.

La crítica ha propuesto que El asco de Horacio Castellanos Moya muestra el desencanto y el cinismo típico de las novelas centroamericanas de "posguerra" que critican el fracaso de los proyectos sociales de carácter utópico. ${ }^{1}$ En este traba- jo, en cambio, se considera $E l$ asco dentro del contexto de un mundo en que el concepto de la nación y específicamente el nacionalismo, en el marco del neoliberalismo, ha entrado en crisis. Por lo tanto arguyo que no hay una estrategia narrativa desencantada que denuncia los errores de la nación, sino una ética que muestra una ruptura con la identidad nacional y el nacionalismo. El protagonista, Edgardo Vega, articula una imaginación global en el sentido que Appadurai considera este término, es decir, como una reformulación de la nación y el patriotismo desde el exterior nutrido por la circulación global de personas y discursos. El punto de vista de Vega excede el paradigma de la nación ya que su monólogo conlleva una perspectiva intensamente transnacional para deshacer la cultura local que conoce desde adentro. Sin embargo, el tono crítico de Vega no debe interpretarse como desencanto, dado que en Vega no hay evidencia de un encanto nacional previo. El monólogo de Vega, en cambio, anuncia una renovada ética humanitaria y cosmopolita que ha reemplazado la identificación nacional.

\section{La imaginación global en $E I$ asco}

La actitud cínica de Edgardo Vega con respecto a su país natal está ligada a su perspectiva global. Arjun Appadurai explica que la circulación global de personas y discursos influye en la subjetividad del individuo que, en vez de imaginarse como un ciudadano de un país, empieza a imaginarse como un socio del mundo. El concepto de la comunidad imaginada de Benedict Anderson ha sido funda- 
mental a partir de la publicación de Imagined Communities (1983). La tesis de este libro en pocas palabras es que la nación no es una unidad esencial, sino una comunidad que sus miembros imaginan. Según Anderson, la mayoría de comunidades no necesitan "imaginar" a los otros miembros de la comunidad porque hay interacción directa entre ellos, pero en la "nación" una gran parte de los ciudadanos nunca se conoce. Los periódicos y otros medios de comunicación hacen posible que la gente que no se conoce sienta que comparten una identidad y que forman parte de una comunidad.
En Modernity at Large (1996), Arjun Appadurai propone una ruptura con la nación y el nacionalismo como productos de la imaginación. Appadurai teoriza que la imaginación global, que representa principalmente como una subjetividad nutrida por los medios de comunicación electrónicos y la migración, rompe con los límites de la comunidad nacional imaginada. Según el autor, la imaginación global trasciende el imaginario de la comunidad nacional dado que toma en cuenta otros mundos posibles:

More people than ever before seem to imagine routinely the possibility that they or their children will live and work in places other than where they were born: this is the wellspring of the increased rates of migration at every level of social, nacional and global life... For migrants, both the politics of adaptation to new environments and the stimulus to move or return are deeply affected by a mass-mediated imaginary that frequently transcends national space. (6)

En su conversación con Moya, Edgardo Vega demuestra que su imaginación excede los límites de la nación y le critica varias veces a Moya por quedarse en el país.
Según Vega, El Salvador es un lugar que "no existe", dado que no se da a ver en las principales publicaciones culturales del mundo:

No entiendo qué hacés aquí, Moya, vos que decís dedicarte a la literatura deberías buscar otros horizontes. Este país no existe, te lo puedo asegurar yo que nací aquí, regularmente recibo las principales publicaciones periódicas del mundo sobre arte, leo con detenimiento las secciones sobre cultura y arte de los principales periódicos y revistas del mundo, por eso te puedo asegurar que este país no existe, al menos artísticamente, nadie sabe nada de él, a nadie le interesa, ningún individuo nacido en este territorio existe en el mun- 
do del arte como no sea por la política o los crímenes, me dijo Vega. Tenes que irte, Moya, zarpar, ubicarte en un país que exista. (72)

Appadurai propone que la circulación de información se intensifica más y más con la tecnología y la diáspora creando imaginarios globales que desplazan las comunidades nacionales. Esta circulación global de información electrónica extien- de la idea de Benedict Anderson de una sola comunidad imaginada basada en el capitalismo de imprenta, a una multiplicidad de mundos imaginados. 2. Esta conciencia global cuestiona el concepto tradicional de "nación":

An important fact of the World we live in today is that many persons on the globe live in such imagined worlds (and not just in imagined communities) and thus are able to contest and sometimes even subvert the imagined worlds of the official mind and of the entrepeneurial mentality that surround them. (Appadurai 33)

La migración de salvadoreños a los Estados Unidos y a Canadá está a la base de la ruptura con la nación y el nacionalismo que representa Edgardo Vega. Por ejemplo, Edgardo vive en Montreal y se distingue de otros salvadoreños que huyen de El Salvador por la situación nacional de guerra o por razones económicas o políticas. Vega explica que se va porque no puede entender por qué alguien viviría en un país tan miserable como él considera que es El Salvador. Edgardo dice que en dieciocho años de vivir fuera de El Salvador nunca le ha hecho falta nada. No siente ninguna nostalgia que tenga que ver con la nación o con una cultura nacional (Castellanos Moya 60).

Al considerar la polémica que levantó El asco en El Salvador, Miguel Huezo Mixco explica, "En este pequeño país, poseedor de un arraigado sentimiento aldeano, no es extraño que el relato de Castellanos provoque animosidades por la manera en que se refiere a la cerveza salvadoreña - bebida "diarreica" - o a las pupusas — "repugnantes tortillas grasosas" ("29 de Julio"). En una entrevista, Castellanos Moya explica su falta de compromiso nacional como un rechazo del patriotismo:

El patriotismo es una estupidez generalizada en todo el planeta, no sólo en América Latina. Creo que el ser humano, entre más diminuto es espiritualmente y más miserable es su cotidianidad, busca aferrarse a valores que lo exalten, 
que le hagan sentir que es importante, más importante que los otros, más importante que los que son diferentes. Y de ahí al ejercicio de la violencia hay apenas un palmo. (Hall)

Como es de esperarse las ideas del autor se proyectan en Edgardo Vega. Según Vega, el "orgullo de nacionalidad" es una característica principal de los pueblos ignorantes porque impide que se juzgue el verdadero valor de las manifestaciones culturales: "...Esa es la primera y principal característica de los pueblos ignorantes, consideran que su miasma es la mejor del mundo, son capaces de matarte si les negás que su miasma, que su mugrosa cerveza diarreica, es la mejor del mundo, me dijo Vega" (12).

El asco representa la perspectiva de un salvadoreño que, como mucha de la población, ha emigrado y regresa con una perspectiva "corrompida" que confirma su salida inicial del país. En vez de sentir la añoranza que se supone en alguien que deja su país, Vega no siente nostalgia de nada. Es más, la experiencia de irse y de vivir en otro país le confirma la inferioridad que ya sospecha en su propio país de nacimiento. La falta de nostalgia pone en cuestión el vínculo entre un ser humano y su tierra natal o adoptiva. Vega no se siente comprometido con una identidad salvadoreña, lo cual socava la estabilidad de la nación imaginada sobre todo en un país como El Salvador donde una gran parte de los ciudadanos viven fuera del país: "A muchos emigrantes les pasa lo mismo. A mí me ha pasado cuando en los 80 viví en Italia y ahora que lo hago en Tegucigalpa. Vemos a El Salvador y realmente, por decir algo suave, da lástima" (Arias).

Además, Vega cuestiona el valor de la cultura nacional salvadoreña que percibe como contaminada por la influencia de flujos de información de los Estados Unidos y de Inglaterra. Para Vega una gran parte de la cultura salvadoreña es nada más que una imitación de estas y otras culturas. Por ejemplo Vega le cuenta a Moya que uno de los principales grupos de música de rock "nacional" sólo tocaba las viejas canciones de grupos ingleses como los Beatles, los Rolling Stones, y Led Zeppelin, y además, en su opinión el grupo "nacional" destrozaba las canciones. Vega repudia la ciudad de San Salvador que para él es una parodia de Los Ángeles y también a los salvadoreños que no quieren nada más que convertirse en gringos. Es a través de su atención a esta imitación cultural que Vega intenta demoler el concepto de una cultura salvadoreña esencial:

Tremendo, Moya, me dijo Vega, San Salvador es una versión grotesca, enana y estúpida de Los Ángeles, poblada por 
gente estúpida que sólo quiere parecerse a los estúpidos que pueblan Los Ángeles, una ciudad que te demuestra la hipocresía congénita de esta raza, la hipocresía que los lleva a desear en lo más íntimo de su alma convertirse en gringos, lo que más desean es convertirse en gringos, te lo juro, Moya, pero no aceptan que su más preciado deseo es convertirse en gringos, porque son hipócritas, y son capaces de matarte si criticas su asquerosa cerveza Pílsener, sus asquerosas pupusas, su asqueroso San Salvador, su asqueroso país, Moya, son capaces de matarte sin parpadear, aunque a ellos no les interese en absoluto y por eso destruyen su ciudad y su país con un entusiasmo enfermizo. (41)

En Estética del cinismo, Beatriz Cortez plantea que la actitud de Moya demuestra el cinismo característico de la sensibilidad de posguerra en Centroamérica. Un modo de sensibilidad que se configura como una alternativa a la sensibilidad utópica y revolucionaria anterior. Es una "sensibilidad del desencanto" que reevalúa críticamente los proyectos revolucionarios y que motiva una reinvención de la subjetividad en el que se "exploran los secretos más oscuros del sujeto, sus pasiones más fuertes, y su negociación con el caos que le rodea" (27). Sin embargo dado que Vega rechaza la comunidad nacional desde antes de la guerra, no se puede caracterizar la sensibilidad de Vega como cinismo en este sentido:

Después llegaron a Montreal miles de tipos siniestros y estúpidos nacidos también en este país, llegaron huyendo de la guerra, buscando mejores condiciones económicas, pero yo estaba allá desde mucho antes, Moya, porque a mí no me corrió la guerra, ni la pobreza, yo no me fui huyendo por la política, sino que simplemente nunca acepté que tuviera el mínimo valor esa estupidez o algún sentido el hecho de ser salvadoreño, por eso me fui, me dijo Vega, y no me metí ni ayudé a ninguno de esos tipos que se decían mis compatriotas, yo no tenía nada que ver con ellos, yo no quería recordar nada de esta mugrosa tierra, yo me fui precisamente para no tener nada que ver con ellos, por eso los evité siempre, me parecían una peste, con sus comités de solidaridad y todas esas estupideces. Nunca pensé volver. (18)

En cambio, Vega representa una imaginación global consciente de que hay otros lugares donde puede hacerse la vida que trascienden la 
comunidad nacional imaginada. La diatriba de Vega contra El Salvador y la cultura nacional salvadoreña se puede entender como un efecto de la circulación de personas y discursos y como parte de una ética cosmopolita renovada que es el enfoque de la segunda parte de este análisis.

\section{La ética cosmopolita en EI asco}

Edgardo Vega representa una renovada ética cosmopolita que desplaza la identificación nacional. Vega es un cosmopolita prototípico, en el sentido que Kwame Anthony Appiah designa como una actitud humanitaria que reconoce las diferencias entre las sociedades mientras enfatiza los puntos que tienen en común. Appiah propone la metáfora de la conversación como un modelo de negociación para poder sobrepasar las diferencias entre las personas y coexistir con tolerancia. El cosmopolitismo tiene sus raíces en la palabra griega "cosmopolitas" que significa "ciudadano del mundo" y es una manera de conceptualizar la ciudadanía en términos globales (xiv). Ejemplo de esto es que el cosmopolitismo es la ética que fundamenta el discurso de los derechos humanos universales en Declaration of the Rights of Man (1789).

Esta tradición de ciudadanía global tiene dos facetas significativas; primero un compromiso con los demás seres humanos que se extiende más allá de los límites del parentesco y de la nación y, en segundo lugar, este cosmopolitismo implica una valoración de y respeto a las diferencias (Appiah xv). De acuerdo a Appiah, en su versión más radical, el cosmopolitismo es imparcial frente los imaginarios donde típicamente se forman los lazos de identificación común como la familia, la escuela, el género sexual y la nación. De modo que el cosmopolita ortodoxo siente iguales la injusticia que experimenta un pariente como el trato injusto de cualquier ser humano. Appiah defiende una actitud cosmopolita menos drástica que no descarta del todo los lazos de parentesco mientras va más allá de estos imaginarios locales. Como es de esperarse, la ética cosmopolita convierte el patriotismo en un valor sin sentido puesto que favorecer a ciertos grupos como la familia o otros ciudadanos implica darle la espalda al resto de la humanidad (Appiah xvi).

El asco se desarrolla dentro del marco de una conversación entre dos personas con diferentes puntos de vista; Edgardo Vega y Moya. Dado su desprecio absoluto por la cultura salvadoreña, la angustia de Vega por encontrar a alguien con quien "platicar" parece fuera de lo natural. Sin embargo, Vega le cuenta a Moya que se decepcionó 
cuando ninguno de sus amigos, excepto Moya, apareció por la funeraria de su madre, y que se dio cuenta entonces de que sólo iba a poder hablar con él. Se presenta en Vega una ansiedad por conversar con el otro. Como se dijo antes, para el cosmopolita la conversación es un hábito de coexistencia y de relacionarse con los demás (Appiah xix) De modo que el deseo de Vega de entablar una conversación con alguien se entiende que brota de la visión cosmopolita:

...Por eso decidí verte aquí, tengo que platicar con vos antes de irme, tengo que decirte lo que pienso de toda esta inmundicia, no hay otra persona a la que le pueda contar mis impresiones, las ideas horribles que he tenido estando aquí, me dijo Vega. (13)

A pesar de que El asco es un monólogo en el que Moya narra lo que Vega le dice, se lee como una conversación entre los dos. Para Vega, el propósito de la conversación es llegar a entenderse con Moya. Vega le cuenta su punto de vista y sus motivos pero también llega a la conversación buscando entender el punto de vista de Moya: "Yo no entiendo qué hacés vos aquí, Moya, ésa es una de las cosas que te quería preguntar, ésa es una de las curiosidades que más me inquietan...explícame, me dijo Vega" (21). La respuesta de Moya no se da en el texto porque la intención de Moya es contar lo que Vega le dijo. Sin embargo, se entiende que hay una conversación entre los dos en la manera en que Vega indaga a Moya.

La ética cosmopolita de Edgardo Vega también se nota en el rechazo a su hermano. Mientras la relación que Vega ha mantenido con su madre muestra que no re- nuncia del todo a los compromisos de parentesco, el hecho de que no siente ningún compromiso con su hermano es significativo. Ivo imagina y supone que hay una relación fraternal entre él y Edgardo Vega, su hermano. Sin embargo, Edgardo rehusa aceptar el mérito de una relación basada exclusivamente en el azar de compartir nada más que la misma sangre y los mismos padres. Edgardo recalca que, aparte de eso, él y su hermano son un par de desconocidos que no tienen nada en común. La actitud de Edgardo concuerda con la de Jean-Jacques Rousseau que en su tiempo acusaron de ser, "a lover of his kind, but a hater of his kindred," por abandonar a sus hijos (Appiah xvi). Este cuestionamiento del compromiso basado en el parentesco se puede entender como una forma radical del cosmopolitismo en el que se hunden los imaginarios locales y nacionales al identificarse con un concepto más abstracto de la humanidad: 
Mí hermano Ivo y yo somos las personas más distintas que podas imaginar, Moya, no nos parecemos absolutamente en nada, no tenemos ninguna cosa en común, nadie creería que somos hijos de la misma madre, somos tan distintos que nunca llegamos a ser amigos, apenas un par de conocidos que compartíamos padres, apellidos y la misma casa, me dijo Vega. Teníamos dieciocho años de no vernos, nunca nos escribimos, apenas intercambiamos saludos y lugares comunes una media docena de veces cuando mi madre me telefoneaba y él estaba con ella, Moya, nunca nos llamamos porque no teníamos nada que hablar, porque cada quien ha podido hacer su vida sin ni siquiera tener que recordar al otro, porque somos completamente extraños, somos las antípodas, la prueba fehaciente de que la sangre no significa nada, la sangre es un azar, algo perfectamente prescindible, me dijo Vega. (36)

La crítica a la fraternidad basada en el parentesco se extiende en El asco al símbolo de ciudadanía transnacional que representa el "Monumento al hermano lejano." Como se explicó antes, Vega no siente ningún compromiso con los demás salvadoreños inmigrantes. Orina metafóricamente en el discurso de un "hermano lejano" que forma parte de la nación a pesar de vivir fuera:

Y el de más adelante es aún peor, Moya, la cosa más horripilante que jamás he visto, ese llamado "Monumento al hermano lejano" parece en realidad un gigantesco mingitorio, ese monumento con su enorme pared de azulejos no evoca otra cosa que un mingitorio, te juro, Moya, que cuando lo vi por primera vez no sentí más que ganas de orinar y cuantas veces he pasado por ese lugar, el asíllamado "Monumento al hermano lejano" no hace otra cosa que excitar mis riñones. Esa es la obra cumbre de la degradación del gusto: un gigantesco mingitorio construido en agradecimiento a los sombrerudos y las regordetas que vienen de Estados Unidos cargados de cajas repletas de los chunches más inusitados, me dijo Vega. (95)

Otro aspecto de la ética cosmopolita que se ejemplifica en Vega es la valoración de la experiencia humana como una expresión que se da a ver en el arte, la literatura y la historia (Appiah 4). En Canadá, Vega es un profesor de la historia del arte y una de las críticas más fuertes 
que hace a la cultura salvadoreña es la falta de expresión artística: "ni libros, ni exposiciones, ni obras de teatro, ni películas, absolutamente nada..." (76). Según Vega, los sal- vadoreños no quieren saber nada que tenga que ver con el cultivo del espíritu y sólo les interesa ver televisión y formar parte de una cultura de consumo:

Horrible, Moya, espeluznante si la miras de cerca: una familia que en sus ratos libres en casa no hace otra cosa que ver televisión, me dijo Vega, no existe un solo libro, mi hermano no tiene un solo libro en su casa, ni la reproducción de alguna pintura, ni siquiera un disco de música seria, nada que tenga que ver con el arte o el buen gusto puede ser encontrado en esa casa, nada que tenga que ver con el cultivo del espíritu puede ser encontrado en ese lugar, nada que tenga que ver con el desarrollo de la inteligencia, es increíble, de las paredes únicamente cuelgan diplomas y estúpidas fotos familiares, y en las repisas de los libreros, en vez de libros, sólo hay de esos adornitos imbéciles que se consiguen en cualquier venta de bisutería, me dijo Vega. (49)

Por otro lado, el pasaporte canadiense marca cierta precariedad en la posibilidad de salir del imaginario nacional y hay la sensación de que este acceso al mundo puede cortarse en cualquier momento. Vega vive en una contexto en que todavía existe la nación, la nacionalidad, y la familia como principios que organizan la experiencia y las relaciones humanas. Por lo tanto cuando Vega cree que ha perdido su pasaporte se aflige de que se le dificulte su salida de El Salvador. De modo que el pasaporte representa su calidad de socio en la comunidad global. Sin el pasaporte él se convierte en un salvadoreño encerrado dentro del imaginario nacional:

El terror se apoderó de mí, Moya, el terror puro y estremecedor: me vi atrapado en esta ciudad para siempre, sin poder regresar a Montreal; me vi de nuevo convertido en un salvadoreño que no tiene otra opción que vegetar en esta inmundicia, me dijo Vega. (114)

Como se ha notado, el pasaporte canadiense le abre el mundo a Edgardo Vega; con ello puede vivir en una ciudad global y separarse de su tierra natal, de su propia historia, y puede hasta asumir una nueva identidad global: 
Incluso durante el trayecto en el taxi me la pasé aferrado a mi pasaporte canadiense, hojeándolo, constatando que ése de la foto era yo, Thomas Bernhard, un ciudadano canadiense nacido hace treinta y ocho años en una ciudad mugrosa llamada San Salvador. Porque esto no te lo había contado, Moya: no sólo cambié de nacionalidad sino también de nombre, me dijo Vega... Mi nombre es Thomas Bernhard, me dijo Vega, un nombre que tomé de un escritor austriaco al que admiro y que seguramente ni vos ni los demás simuladores de esta infame provincia conocen. (118)

De hecho, el pasaporte significa que Edgardo Vega ha reformulado su identidad para transformarse en Thomas Bernhard, un escritor austriaco que forma parte del imaginario global de Vega. Es más, es significativo el hecho de que Vega se nombra a si mismo porque esto marca un rechazo del proceso de interpelación; contradice la autoridad que, al designarlo Edgardo Vega, primero lo Ilamó a ser un sujeto de la comunidad nacional imaginada. ${ }^{3 .}$

\section{Conclusión}

A modo de conclusión retomo la "estética del cinismo" que Beatriz Cortez define como la producción cultural ligada al desencanto con los procesos revolucionarios centroamericanos que se dan a partir de la segunda mitad del siglo veinte (24). Esta manera de leer la producción cultural es problemática porque el desencanto impone un discurso que no necesariamente le corresponde a la producción artística y cultural y que limita la posibilidad de reconocer en el texto la realidad centroamericana que se expresa. Cuando se trata de El asco de Horacio Castellanos
Moya, la novela no representa una sensibilidad desencantada de posguerra. Como se ha notado, el protagonista indica sin ambages que no dejó el país por la política ni por la guerra sino más bien porque el país, desde antes de la guerra, le daba asco. Debo aclarar que no niego el tono cínico de Edgardo Vega ni la manera en que su diatriba destroza la cultura salvadoreña, pero su tono se debe, no al desencanto, sino a una ética cosmopolita y a la "contaminación" del imaginario nacional por los flujos globales de personas y de información. 
Bibliografía

- Althusser, Louis. "Ideology and Ideological State Apparatuses" in Lenin and Philosophy and Other Essays. Monthly Review Press, 1972.

- Anderson, Benedict R. O'G. Imagined Communities: Reflections on the Origin and Spread of Nationalism. London: Verso, 1991. Print.

- Appadurai, Arjun. Modernity at Large: Cultural Dimensions of Globalization. Minneapolis, MN: University of Minnesota, 1996.

- Appiah, Anthony. Cosmopolitanism: Ethics in a World of Strangers. New York: W.W. Norton \&, 2006.

- Arias, Carlos. "Anónimo dijo". Web log comment. Talpajocote. Miguel Huezo Mixco, 8 de junio de 2008. Web. 20 Nov. 2012.

- Castellanos-Moya, Horacio. El asco: Thomas Bernhard en San Salvador. San Salvador, El Salvador: Editorial Arcoiris, 1997.

- Cortez, Beatriz. Estética del cinismo: Pasión y desencanto en la literatura centroamericana de posguerra. Guatemala, Guatemala: F\&G Editores, 2010.

- Hall, Lillian F. "Horacio Castellanos Moya: El patriotismo es una estupidez generalizada en todo el planeta." Letralia 217 (2009): n. pag. Web.

- Poblet, Natu, dir. "Horacio Castellanos Moya: El asco y Baile con serpientes." Leer es un placer. Buenos Aires, Argentina, 11 de julio de 2012. Radio.

- " "29 de julio a las 6:30, conversatorio con Horacio Castellanos Moya." El País: Por el desarrollo de El Salvador. N.p., 27 de julio de 2010. Web. 30 Nov. 2012. 
Notas

1 Horacios Castellanos Moya pertenece a

created the possibility of a new form la llamada Generación del Cinismo o of imagined community, which in its Generación del Desencanto, junto con Rafael Menjívar Ochoa, Jacinta Escudos, Claudia Hernández y Miguel Huezo Mixco, entre otros que comenzaron su producción literaria en la época de la guerra.

2 Según Benedict Anderson en Imagined Communities "...the convergence of capitalism and print technology on the fatal diversity of human language basic morphology set the stage for the modern nation." (46)

3 Louis Althusser define el proceso de interpelación en "Ideology and Ideological State Apparatuses." El sujeto es constituido por una autoridad externa cuando el sujeto responde a su interpelación como un sujeto, y así acepta la autoridad de otro de nombrarlo y su posición determinada dentro de la sociedad (174). 